ELEMEN ESTETIS KOREOGRAFI TARI CANG-CANG DI KAYUAGUNG KABUPATEN OGAN KOMERING ILIR

Emy Admala Yuliarti

KONSEP KEBERSAMAAN DALAM TRADISI MIDANG MABANG HANDAK PADA MASYRAKAT MORGESIWE KECAMATAN KAYUAGUNG

A. Heryanto

PANGLIMA LAOQT SEBAGAI LOCAL WISDOM MASYARAKAT NELAYAN PESISIR ACEH (STUDI KASUS TENTANG PANGLIMA LAOQT LHOK KECAMATAN SERUWAY KABUPATEN ACEH TAMIANG)

Purnama Sari \& Puspitawati

PENERAPAN MODEL PEMBELAJARAN COURSE REVIEW HORAY TERHADAP KEMAMPUAN MENJELASKAN ALUR CERPEN UNTUK ANAK SDN 52 PALEMBANG Sri Wahyu indrawati

PENGARUH MODEL PEMBELAJARAN ARTIKULASI TERHADAP KEMAMPUAN MENULIS PADA SMP NEGERI 2 PALEMBANG

Yus Vernandes Uzer

PENGARUH MODEL PEMBELAJARAN COMPLETE SENTENCE TERHADAP KEMAMPUAN MENULIS PADA SMP NEGERI 13 PALEMBANG

Yuspar Uzer

$60-70$

PENGARUH MUSIK ANSAMBEL TERHADAP KECERDASAN EMOSI REMAJA

Novdaly Fillamenta \& Mohammad Arfani

PEWAISAN RABAB PIAMAN DI KECAMATAN LUBUK ALUNG

KABUPTEN PADANG PARIAMAN

Irfan Kurniawan

$82-93$

ESTETIKA MOTIF NAGO BESAUNG PADA KAIN SONGKET PALEMBANG Decky Kunian

BENTUK GERAK TARI KAIN DI SANGGAR DEWAN KESENIAN MUSI RAWAS

Pransiska Sepriyanti 


\title{
PEWARISAN RABAB PIAMANDI KECAMATAN LUBUK ALUNG KABUPTEN PADANG PARIAMAN
}

\author{
Oleh: \\ Irfan Kurniawan \\ (Dosen FKIP Universitas Pgri Palembang)
}

\begin{abstract}
Abstrak
Penelitian ini bertujuan untuk mengungkap kondisi Rabab Piaman dalam kehidupan masyarakat dewasa ini dan pewarisannya dalam kehidupan masyarakat di Kecamatan Lubuk Alung, Kabupaten Padang Pariaman. Kenyataannya yang ditemukan sekarang seniman tradisi Rabab Piaman bertarung melawan perubahan nilai akibat modrenisasi, yang mengakibatkan menurunya eksistensi pertunjukanya dalam masyarakat kecamatan Lubuk Alung. Peneliti menggunakan pendekatan kualitatif dengan mengkuti langkah-langkah Miles dan Huberman. Pengumpulan data dilakukan dengan obervasi, wawancara, dan dokumentasi. Hasil penelitian ini menunjukkan bahwa pewarisan Rabab Piaman terdiri dari bagian-bagian yang saling terkait satu sama lainnya, yaitu pewarisan enkulturasi dan pewarisan sosialisasi. Selanjutnya, dari hasil penelelitian juga ditemukan bahwa sistem pewarisan Rabab Piaman di kecamatan Lubuk Alung mempunyai cara tersendiri. Secara tradisi ada dua tahapan dalam pewarisan Rabab Piaman di Nagari Lubuk alung, yaitu; (1) pewarisan secara non fisik, yakni Melengkapi syarat-syarat baraja (belajar) Rabab Piaman, dan (2) pewarisan secara fisik, yakni praktik belajar memainkan Rabab Piaman.
\end{abstract}

Kata Kunci: Pewarisan, Rabab Piaman, kecamatan Lubuk Alun.

\section{A. PENDAHULUAN}

Minangkabau sangat kaya akan seni tradisi dan budayanya, salah satunya adalah musik tradisional Rabab Piaman. Kesenian Rabab Piaman sangat eksis dalam konteks kehidupan pendukungnya terutama masyarakat Pariaman pada era terutama pada era 60an sampai 80-an. Eksistensi Rabab Piaman tersebut tergambar dalam ungkapan masyarakatya (LKAAM, $\begin{array}{lll}\text { 1987:189); } & \text { Bapupuik jo } \\ \text { batalempong, } & \text { basaluang jo }\end{array}$ barabab sarato bagandang basaliguri (berpupuik dan bertalempong, bersaluang dan berebab, serta bergendang bersaliguri), dari ungkapan tersebut dipahami musik tradisi tersebut merupakan kesenian utama untuk melengkapi kebutuhan selera estetis masyarakatnya.

Musik Tradisional Rabab 
Piaman adalah seni pertunjukan yang menggunakan instrumen rabab (sejenis alat musik gesek klasifikasi kordofon jenis long necked spike fiddle) yang dalam penyajianya berfungsi untuk mengiringi kaba (jenis sastra lisan cerita rakyat minangkabau) yang dituturkan melalui musik vokal. Selanjutnya

Kurniawan menjelaskan bahwa terdapat juga penyajian yang tidak berbentuk seni tutur tetapi hanya menyanyikan melodi yang berbentuk strophic ${ }^{1}$ dengan sumber teks berasal dari pantunpantun yang spontan sehingga melahirkan sifat penyajian yang logogenik2. Dalam penyajiannya hanya terdiri atas satu alat instrumen saja yaitu instrumen Rabab,. Artinya tidak ada alat instrumen lain yang melengkapinya. Teknik penyajian antara melodi rabab dengan melodi dendang bersifat heterophony ${ }^{3}$ terhadap melodi lagu yang disajikan. Artinya

\footnotetext{
1 Suatu melodi pendek yang dinyanyikan secara berulang-ulang dengan memakai rangkap teks pantun yang berbeda-beda.

${ }^{2}$ Teks pantun dalam penyajian melodi yang bersifat strophic didasarkan atas kecakapan melahirkannya secara spontan.

${ }^{3}$ Berangkat dari satu dasar melodi, tetapi dipraktekkan dengan garapan yang berlainan.
}

instrumen musik melodi yang bersifat tunggal namun penyajiannya berduet mengiringi vokal (lagu) (Kurniawan, 2016, hal. 61)

Pada awalnya kesenian rabab ini sangat penting kehadiranya dalam berbagai koteks upacara dan acara hiburan masyarakat terutama di kabupaten padang pariaman, seperti upacara pengangkatan panghulu (kepala adat), resepsi perkawinan, sunat rasul, peresmian lembaga dan berbagai acara hiburan lainya.

Seiring dengan pesatnya perkembangan dan meluasnya wilayah pertunjukan rarab piaman dan didukung oleh apresiasi masyarakat perantau pariaman yang ada diseluruh wilayah di Minangkabau, sehingga pada masa itu Rabab Piaman dijumpai hampir di seluruh wilayah minangkabau. Begitu kuatnya eksistensi Rabab Piaman di berbagai daerah di minangkabau, sehingga mengilhami lahirnhya berbagai jenis kesenian rabab di Minangkabau seperti Rabab Darek, Rabab Bangkinang, Rabab Badoi. 
Hal yang cukup

memprihatinkan terjadi sesudah dekade 90an, dimana terjadi kemunduran yang cukup drastis. Boleh dikatakan, dewasa ini kesenian Rabab Piaman memasuki dekade involusi (kemandegan, kemunduran) dari segala aspek kehidupannya, sehingga berdampak terhadap kelangkaan pewaris, sekaligus kehilangan konteksnya. Kenyataannya yang ditemukan sekarang kecamatan Lubuk Alung Padang Pariaman, seniman tradisi Rabab Piaman bertarung melawan perubahan-perubahan nilai akibat modrenisasi maupun akibat intervensi media elektronik dan digital yang mampu merasuk ke desa-desa terpencil. Dalam hal ini kesenian tradisi Rabab Piaman semakin lama semakin kurang penampilanya di tengahtengah masyarakat Lubuk Alung. Hal ini terjadi karena cara hidup, dan kebutuhan hidup masyarakat pendukungnya semakin berubah yang dipengaruhi oleh modrenisasi.

Sejalan dengan hal tersebut Kurniawan menjelaskan Era globalisasi dan komunikasi yang telah masuk ke dalam berbagai aspek kehidupan, di satu sisi membawa kemudahan bagi gerak kehidupan, di sisi yang lain berdampak pada kemunduran bahkan kepunahan bagi beberapa unsur dan aspek kebudayaan. Saat ini arus globalisasi (teknologi, informasi dan komunikasi) mengakibatkan terjadinya perubahan sosial pada masyarakat Pariaman, dimana individu-individu dalam masyarakat melakukankan penyesuaian perilaku dan tindakan berdasarkan ciri globalisasi tersebut, akan tetapi penyerapan konsep-konsep globalisasi itu dilakukan tanpa mempertimbangkan nilai-nilai budaya lokal sehingga berdampak pada kemunduran (Kurniawan, 2016, hal. 10).

Berbagai upaya telah dilakukan seniman Rabab Piaman agar kesenian tradisi Rabab Piaman tidak hilang keberadaanya akibat pengaruh modrenisasi atau arus budaya popular. Salah satunya dengan melakukan pewarisan Rabab Piaman 
terhadap generasi muda sebagai generisi penerusnya. Terkait dengan itu, tukang rabab Monen (65 th) menjelaskan, sejak tahun 90an hingga sekarang sangat langka pewaris Rabab Piaman, sedangkan para tukang rabab (seniman rabab) yang senior sudah banyak yang meninggal. Adapun tukang rabab satu angkatan dengannya hanya tersisa tiga orang, dan itupun tidak begitu aktif lagi karena sudah tua. Saat ini harapan tertumpu pada 4 orang muridnya yang sedang manuntuik (berguru) denganya. Jika empat orang ini tidak berhasil, maka la mengkhawatirkan kesenian Rabab Piaman akan punah, karena tidak ada lagi yang bisa mewariskan kesenian rabab kedepanya (wawancara, 18 desember 2018).

Berdasarkan fenomena di atas, terkait dengan kondisi seni pertunjukan Rabab Piaman dan pewarisanya, penelitian dan pendokumentasian sistem pewarisan kesenian Rabab Piaman di Kecamatan lubuk Alung Kabupaten Padang Pariaman menjadi penting untuk di kaji.

\section{B. METODE PENELITIAN}

Metode yang digunakan dalam penelitian "Pewarisan Rabab Pariaman di Kecamatan Lubuk Alung, Kabupaten Padang Pariaman" adalah metode penelitian kualitatif.

Penggunaan metode kualitatif dilakukan dengan pertimbangan bahwa penulis mengkaji lebih mendalam fenomena-fenomena yang terjadi dalam lingkungan masyarakat. Sesuai yang dikemukakan Miles dan Huberman bahwa penelitian kualitatif dilakukan untuk mendapatkan informasi tentang fenomena yang sedang berlangsung (Miles dan Huberman, 1992: 37). Penelitian kaulitatif yang di defenisikan oleh Bogdan dan Taylor adalah "sebagai prosedur yang menghasilkan data deskritif berupa kata-kata tertulis atau lisan dari orang-orang dan prilaku yang di amati (Dalam Maleong, 2000: 3). Metode ini dipilih berdasarkan atas permasalahan dan tujuan penelitian.

Seperti halnya yang 
dilakukan penulis turun pewarisan kesenian tradisi Rabab kelapangan dan mengamati langsuang kejadian yang sedang terjadi, dan bertemu langsung dengan beberapa orang seniman Rabab Pariaman yang masih aktif hingga saat ini dan melakukan wawancara membahas permasalahan yang sedang penulis teliti yaitu tentang keadaan Rabab Pariaman dalam kehidupan masyarkat dewasa ini, dan bagaimana cara pewarisan Rabab Pariaman di Nagari Pasie Laweh, Kecamatan Lubuk Alung, Kabupaten Padang Pariaman.

\section{HASIL PENELITIAN DAN PEMBAHASAN}

\section{Pewarisan Rabab Piaman di Nagari Lubuk alung}

Pewarisan budaya (transmission of culture) yaitu proses pembelajaran dan penyesuaian pola tindakan budaya dari satu individu dengan individu lain dilingkungan sosialnya. Pewarisan budaya dapat berupa bahasa, adat istiadat, teknologi, kesenian, dan sebagainya. Pewarisan budaya yang dimaksud di sini adalah

Piaman dalam konteks budaya masyarakat Lubuk Alung yang terus diupayakan berkembang ke generasi berikutnya agar tidak hilang atau punah diterjang oleh kebudayaan yang baru. Proses pewarisan budaya secara umum terjadi melalaui dua proses yaitu proses enkulturasi dan proses sosialisasi.

Koentjaraninggarat (2009: 186-189) menjelaskan bahwa proses pewarisan kebudayaan secara sosialisasi sosialisasi sangat erat kaitannya dengan proses belajar kebudayaan dalam hubungannya dengan sitem sosial. Dalam proses ini "seorang individu mulai dari masa kanakkanak masa dewasa, hingga masa tuanya, belajar bermacammacam pola tindakan dalam interaksi dengan banyak individu dilingkunganya yang menduduki bermacam-macam status dan peranan sosialnya yang ada dalam kehidupan masyarakat sehari-hari”. Sedangkan pewarisan budaya secara enkulturasi adalah proses seorang individu mempelajari dan 
menyesuaikan alam pikiran serta sikapnya dengan adat, sistem norma, dan peraturan yang hidup dalam kebudayaanya. Proses ini dimulai sejak kecil, mulai dari meniru pola tindakan keluarga, teman, dan masyarakat dilingkunganya, kemudian nilai tersebut diserap dalam kepribadianya, sehingga menjadi pola yang mantap dan norma yang mengatur tindakanya dibudayakan

Berkaitan dengan pewarisan kesenian tradisional Sedyawati (2014:186) menjelaskan bahwa:

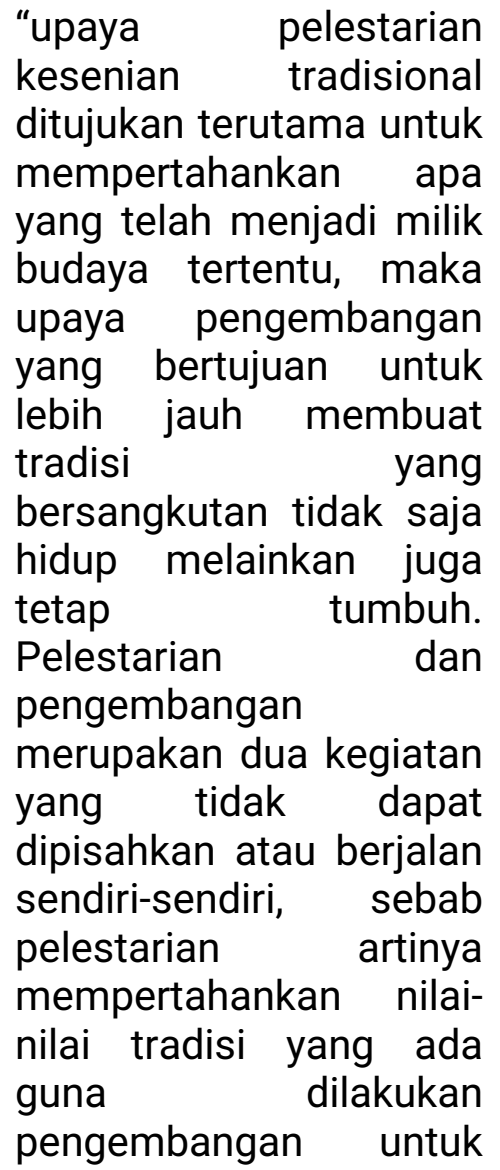

mempertahankan dalam

berkembangnya zaman."

Menurut Hari Poerwanto dalam bukunya yang berjudul Kebudayaan dan Lingkungan menyatakan bahwa "Manusia dan kebudayaan merupakan kesatuan yang tidak terpisahkan, dan makhluk manusia merupakan pendukung kebudayaan. Sekalipun makhluk manusia akan mati, tetapi kebudaayan yang dimilikinya akan diwariskan untuk keturunanya, demikian seterusnya. Pewarisan kebudayaan makhluk manusia, tidak hanya terjadi secara vertikal atau kepada anak cucu mereka, melainkan dapat pula dilakukan secara horizontal atau manusia yang satu dapat belajar kebudaayan dari manusia lainnya" (Poerwanto, 2006: 87).

Pewarisan Rabab Piaman dalam masyarakat tradisional yang ada di Nagari Lubuk alung memakai kedua sistem yang di kemukakan oleh Hari Poerwanto sistem pewarisan secara vertikal dan horizontal, yaitu diwariskan dari Ayah ke anak, atau dari mamak (paman) ke Kemanakan (keponakan), kaka ke adik dan 
juga ada belajar dari masyarakat yang satu ke masyarakat lainnya. Terkait dengan itu Monen (seniman Rabab Piaman) menjelaskan bahwa "ia tidak menutup kemungkinan untuk siapa saja yang ingin belajar kesenian Rabab Piaman, karna sudah kewajibanya juga untuk mewariskan kesenian ini kepada generasi berikutnya. Karena kalau kesenian ini tidak diwariskan, dikhawatikan kesenian ini akan hilang dan hanya tinggal kenangan saja. Selanjutnya ia menjelaskan bahwa saat ini ada empat orang yang belajar kesenian Rabab Piaman, dari empat orang muridnya yang belajar kesenian Rabab tersebut. Tiga orang di antara muridnya masih ada hubungan persaudaran dengan Monen, yaitu Emradin (adik), Harminto dan Aan (anak) Sedangkan Bang Badun tidak punya hubungan persaudaraan dengan Monen ( wawancara, 16 desember 2018).

Pewarisan Rabab Piaman yang dimaksud dalam tulisan ini merupakan salah satu usaha atau langkah yang perlu dilakukan agar kesenian tradisi khususnya Rabab Piaman dapat tetap hidup dan berkembang dalam kehidupan masyarakatnya. Secara tradisi pewarisan Rabab Piaman yang pernah dilakukan oleh senimannya adalah sangat tergantung kepada minat bagi yang ingin belajar Rabab Piaman. Pembelajarannya dilakukan secara Oral, dimana murid menirukan apa yang di ajarkan oleh gurunya. Dalam kaitan ini, ada dua unsur penting yang harus ada untuk pewarisan sebagaimana yang dimaksud yaitu harus ada orang yang akan mewariskan dan harus ada pula orang yang menerima warisan. Walaupun kedua unsur tersebut sudah ada, apabila tidak didukung oleh kemauan yang tinggi dan tekad yang kuat dari kedua unsur tersebut, tentu saja pewarisan terhadap kesenian tradisi khususnya Rabab Piaman tidak akan bisa tercapai.

Secara tradisional, seniman Rabab Piaman di kecamatan Lubuk Alung mempunyai cara tersendiri dalam pewarisan kesenian seni tradisinya. Secara 
tradisi ada dua tahapan dalam pewarisan Rabab Piaman di kecamatan Lubuk Alung, yaitu; (1) pewarisan secara non fisik, yakni Melengkapi syarat-syarat baraja (belajar) Rabab Piaman, dan (2) pewarisan secara fisik, yakni praktik belajar memainkan $R a b a b$ Piaman.

\section{a. Pewarisan Secara Non Fisik}

Untuk belajar kesenian Rabab Piaman, ada semacam ritual-ritual atau prosesi tertentu yang harus dilakukan oleh seseorang yang ingin belajar kesenian ini. Ritual yang diyakini dan masih dipakai sampai saat sekarang adalah membaca mantra yang berkaitan dengan kekuatan gaib.

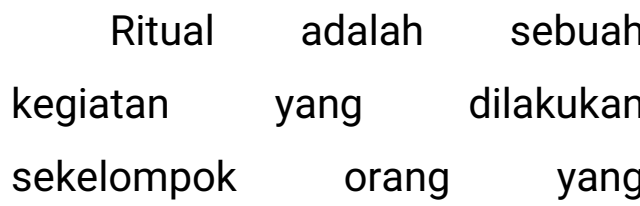
berhubungan terhadap keyakinan dan kepercayaan spritual dengan suatu tujuan tertentu (Situmorang, 2004:175). Biasanya ritual ini dilakukan oleh orang yang akan mewariskan Rabab Piaman kepada orang yang ingin belajar Rabab Piaman yang secara tradisi dikenal dengan istilah "baguru" (berguru) atau "manuntuik" (menuntut 'ilmu'). Dalam kaitan ini, bagi orang yang ingin belajar Rabab Piaman harus memenuhi syarat-syarat sebagai berikut:

\section{1) Menyemblih Ayam}

Prosesi ini dilakukan guru rabab dengan menyembelih ayam hitam dan putih dan membaca mantra tertentu. Prosesi ini berfungsi untuk ketahanan ilmu baik secara lahir maupun batin bagi seseorang yang ingin menjadi tukang rabab. Di samping itu, juga berfungsi sebagai pakasiah dalam artian agar setiap orang yang menyaksikan pertunjukan rabab menjadi tertarik dan senang terhadap pertunjukan rabab. Pakasiah (pemikat) ini ditujukan kepada penikmat kesenian ini agar kesenian ini disenangi oleh masyarakat yang menyaksikan dan mendengarkannya.

\section{2) Membakar kemenyan}

Sama halnya dengan prosesi penyembelihan ayam, pembakaran kemenyan juga 
mempunyai fungsi tertentu dalam kegiatan ritualnya. Kemenyan biasanya dibakar oleh guru dan diasapkan kepada murid yang akan belajar. Prosesnya yaitu tangan dan jari si murid diasapi dengan asap kemenyan sambil dibacakan mantra-mantra. Hal ini diyakini tangan dan jari murid yang belajar rabab menjadi ringan atau lentur dan tidak kaku dalam memainkan Rabab Piaman. Prosesi ini berlaku kepada setiap orang yang ingin belajar Rabab Piaman. Proses ini harus dilalui dulu sebelum masuk tahap pembelajaran yang lebih lanjut. Ritual ini menggunakan mantra yang diyakini oleh masyarakatnya mempunyai kekuatan gaib, yang sampai saat ini masih diyakini oleh masyarakatnya dan sukar untuk melepaskan. Cara pewarisan Rabab Piaman ini dipandang oleh masyarakat kecamatan Lubuk Alung mengandung unsur magis.

\section{3) Mandoa}

Proses yang terkhir adalah Mando'a (membaca doa), prosesi mendoa dilakukan di rumah murid yang dilakukan untuk memohon restu kepada Allah agar individu yang sedang belajar diberi kemudahan dalam belajar Rabab Piaman. Biasanya ritual mandoa ini dilakukan setelah murid bisa memainkan satu atau dua repertoar lagu atau dendang.

\section{b. Pewarisan Bersifat Fisik (Teknis)}

Pembelajaran Rabab Piaman secara teknis dilakukan melalui lima tahapan yaitu : (1) Teknik menggesek rabab, (2) teknik manstel rabab, (3) teknik penjarian, (4) penyajian melodi dan, (5) penguasaan kaba.

\section{1) Teknik Menggesek Rabab Piaman}

Teknik manggesek rarab merupakan langkah awal dalam belajar kesenian Rabab Piaman, dimana murid diajarkan teknik memegang panggesek, dan teknik menggesekan rabab. Teknik memegang panggesek yakni, di pegang dengan tangan kanan, posisi jari memegang pangkal panggesek dengan posisi 
panggesek direbahkan (horizontal) sejajar perut dengan kemiringan 110 sampai 120 derajat. Pada saat memainkan rabab tali panggesek dijepit dengan jari sehingga tali menjadi tegang. Cara ini dalakukan untuk menghasilkan bunyi yang maksimal atau bunyi yang bulat (bulek).

Teknik menggesek rabab dilakukan dengan cara mengayunkan panggesek (dengan menggunakan elastisitas pergelangan tangan) ke kiri dan ke kanan pada tali rabab, dengan posisi rabab tegak dengan kemiringan 60 sampai 70 derajat.

Ada tiga teknik dalam menggesek rabab yaitu, teknik gesek panjang, teknik gesek pendek, dan teknik gesek terputus -putus. Panjang pendek dan terputus-putusnya gesekan dilakukan, tergantung pada jenis melodi lagu atau dendang yang dimainkan.

\section{2) Manstel (Tuning) Rabab Piaman}

Tuning atau Manste/ rabab adalah mencari atau menentukan bunyi dari masing-masing tali rabab, artinya tiga tali pada rabab mempunyai tingkatan bunyi yang berbeda. Manstel bunyi Rabab Piaman tidak mempunyai tolak ukur yang baku, melainkan berdasarkan pada pertimbangan raso (rasa) estetis dari seniman rabab. Terkait dengan hal tersebut Hajizar dalam tulisanya yang berjudul "Tradisi Pertunjukan Rabab Minangkabau" menjelaskan tentang tuning tali Rabab Piaman (1998: 48) yaitu:

a. "Tali Udang ( Tali Satu) : $\mathrm{E} 4+4 \mathrm{~Hz}$ $329.63+4=333.63 \mathrm{~Hz}$ $\mathrm{E} 4=333.63 \mathrm{~Hz}$

b. Tali Sajrah ( Tali Dua) $\mathrm{B} 3+6 \mathrm{~Hz}$ $246.94+6=252.94 \mathrm{~Hz}$ B3 $=252.94 \mathrm{~Hz}$

C. Tali Aguang: Fis $3+5 \mathrm{~Hz}$ $185.00+5=190.00 \mathrm{~Hz}$ Fis3 $=190.00 \mathrm{~Hz}^{\prime \prime}$

3) Teknik Penjarian Dalam Memainkan Melodi

Teknik penjarian adalah teknik memainkan tali rabab pada batang rabab (FingerBoard) yang 
dilakukan dengan tangan kiri pada saat menyajikan melodi lagu pada Rabab Piaman. Tangan memegang batang rabab (seperti menggenggam) dengan posisi ibu jari berada dibelakang batang rabab, serta empat jari lainnya (telunjuk, jari tengah, jari manis, dan kelingking) memainkan tali rabab yang berada di atas bagian depan batang rabab (di atas Fingerboard). Teknik penjarian yang benar dapat diidentifikasi dari bunyi yang dihasilkan. Kualitas bunyi yang baik dihasilkan dari ketepatan jari dalam menekan (memainkan) tali rabab. Adapun salah satu contoh teknik penjarian adalah garitiak (ornamen melodi). Garitiak dilakukan dengan cara menekan dan mengangkat jari secara cepat pada tali rabab (sejenis triler), untuk memberikan ornamentasi pada melodi lagu, yang dalam penyajian Rabab Piaman juga di istilahkan dengan bunyi garitiak.

\section{4) Teknik Melodi}

Untuk

mencapai

kemampuan dalam menyajikan melodi Rabab Piaman ada tiga aspek yang perlu diperhatikan yaitu : (1) Mengenal Wilayah nada, (2) mengenal fungsi tali rabab dalm penyajian melodi (3) cara penyajian antara melodi rabab dan melodi vocal.

(1) Mengenal wilayah nada yang terdapat pada Rabab Piaman. Menurut Hajizar pada prinsipnya tangga nada Rabab Piaman adalah pentatonic (lima tingkatan nada) yakni, tingkatan nada pertama, tingkatan nada kedua, tingkatan nada ketiga, tingkatan nada keempat dan tingkatan nada kelima. Dengan perkiraan interval sebagi berikut:

a. Nada Pertama : E4+4 $\mathrm{Hz}$

$E 4=329.63+4=$ $333.63 \mathrm{~Hz}$

b. Nada Kedua : F4 - $2 \mathrm{~Hz}$ $\mathrm{F} 4=349.23-2=$ $347.23 \mathrm{~Hz}$

c. Nada Ketiga : G4 $+9 \mathrm{~Hz}$ $\mathrm{G} 4=392.00+9=$ $401.00 \mathrm{~Hz}$

d. Nada Keempat : Gis4 + $2 \mathrm{~Hz}$ 
Gis4 $=45.30+2=$

$417.30 \mathrm{~Hz}$

e. Nada Kelima : Ais $4+3$

$\mathrm{Hz}$

Ais4 $=466.16+3=$

469.16 Hz (1998: 48).

jarak nada pertama ke nada kedua sekitar 100cen (setengah nada), jarak nada kedua dengan nada ketiga 200cen (satu nada), jarak nada ketiga dengan nada empat 100cen (setengah nada), jara nada ke empat ke nada kelima 200cen (satu nada).

(2) Mengenal fungsi tali rabab, Penyajian melodi pokok dalam permainan rabab lebih cendrung dimainkan pada tali satu, sedangkan tali dua digunakan untuk memberikan variasi setelah kalimat melodi, dan tali tiga berfungsi untuk menghasilkan bunyi drone atau bunyi panjang dengan cara lose senar (tidak menekan tali rabab dengan jari). Pada saat memainkan melodi pada tali satu terkadang tali dua berfungsi sebagai drone. Sedangakan saat memainkan variasi melodi pada tali dua, tali tiga berfungsi sebagai drone.

(3) Cara penyajian antara melodi rabab dan melodi vocal; secara umum ada tiga bentuk penyajian melodi rabab dengan melodi vocal yaitu ; pertama, melodi rabab sebagai pengantar melodi lagu, kedua, penyajian melodi rabab mengikuti melodi vocal, ketiga, melodi rabab tidak mengikuti melodi lagu, akan tetapi mengiringi dengan memberikan variasi pada melodi lagu dalam wilayah nada yang sama, seperti memainkan nada-nada panjang sebagai background, dan memberikan aksen-aksen tertentu.

\section{5) Penguasaan Kaba /}

\section{Cerita}

Untuk menguasai kaba ada tiga tahapan yang harus dilewati oleh 
pemain rabab yaitu :

(1) Banyak mengapresiasi kaba-kaba, dengan melihat secara langsung pertunjukan rabab maupun mendengar dari rekaman.

(2) Menghafal kaba dan pantun-pantun

(3) Memahami dan menghayati jalan cerita kaba

Dengan menguasai tiga tahapan di atas, pemain rabab akan mampu menyajikan kaba dengan baik, dan bisa menyajikan kaba dengan gaya bahasa sendiri, dan bahkan bisa membuat cerita atau kaba sendiri

Langkah-langkah dalam
belajar Rabab $\quad$ Piaman
sebagaimana diuraikan di atas,
tidak ada standar baku dalam
pewarisan (mengajarkan)
Piaman untuk mencapai
kemampuan
menyajikannya atau kemampuan
menjadi tukang rabab. Akan tetapi
pewarisan dan pembelajaran lebih
ditekankan pada aspek

pertimbangan rasa estetis oleh guru Rabab Piaman.

Dalam proses belajar Rabab Piaman, setiap murid diharuskan datang kerumah guru yang akan mengajarkannya, sesuai dengan waktu atau jadwal yang telah ditentukan. Tidak hanya itu, murid yang akan belajar juga sering di ajak untuk ikut dalam pertunjukan Rabab Piaman seperti dalam acara-acara perhelatan. Murid yang sudah bisa memainkan satu atau dua buah dendang, diberi kesempatan untuk tampil. Hal ini dilakukan supaya murid paham tentang cara -cara pertunjukan yang akan dilakukan dan menambah pengalaman saat tampil di depan umum, seperti yang disampaikan oleh Am salah seorang seniman Rabab Piaman, bahwa setiap murid harus berani tampil di depan umum. Begitulah proses belajar atau proses mewarisi kesenian Rabab Piaman di Nagari Lubuk alung Lubuk Alung yang dilakukan kepada setiap generasinya. 
D. KESIMPULAN

Berdasarkan uraian hasil penelitian Musik tradisi Rabab Piaman yang pada masa lalu sangat eksis di Minangkabau, sejak awall 90-an mengalami kemunduran yang sangat drastis, hal tersebut dapat dilihat dari menurunya intensitas pertunjukan, menyempitnya wilayah pertunjukan dan kelangkaan pewarinya. Saat ini hanya terdapat 3 orang seniman Rabab Piaman, dari ketiga tukang Rabab Piaman tersebut hanya 1 orang yang masih aktif.

Terkait dengan kondisi menurunya eksistensi Rabab Piaman, berbagai upaya dilakukan seniman rabab agar tetap bertahan, salah satunya dengan melakukan pewarisan. Saat ini terdapat 4 orang pewaris kesenian Rabab Piaman yang sedang belajar.

Dari hasil penelitian ditemui seniman Rabab Piaman di kecamatan Lubuk Alung mempunyai cara tersendiri dalam pewarisan kesenian seni tradisinya. Secara tradisi ada dua tahapan dalam pewarisan Rabab Piaman di kecamatan Lubuk Alung, yaitu; (1) pewarisan secara non fisik, yakni Melengkapi syaratsyarat baraja (belajar) Rabab Piaman, dan (2) pewarisan secara fisik, yakni praktik belajar memainkan Rabab Piaman.

\section{DAFTAR PUSTAKA}

Arafah, B. (2003). Warisan Budaya, Pelestarian dan Pemanfaatannya. Artikel, Fakultas IImu Budaya UNHAS.

Hajizar, 1998. Tradisi Pertunjukan Rabab Minangkabau. Bandung: MSPI. Hal 39.

Hajizar, H. (2019). Tradisi Musik Rabab Di Daerah Pesisir Minangkabau (Rabab Piaman Dan Rabab Pasisia). Laga-Laga: Jurnal Seni Pertunjukan, 5(2), 184200.

Kurniawan, I. (2019). Ketermarginalan Seni Pertunjukan Rabab Piaman Di Kecamatan Lubuk Alung Pariaman Sumatera Barat. Jurnal sitakara, 4(1).

Kurniawan, I. (2016). Kontradiksi Kebijakan Industri Kreatif Dan Usaha Pelestarian Kesenian Tradisi (Kasus Seni Pertunjukan Luambek). Besaung: Jurnal Seni, Desain dan Budaya, 1(2). 
LKAAM, 1987. Pelajaran Adat Minangkabau (Sejarah dan budaya). Padang: LKAAM.

Koentjaraninggrat, 2009, Pengantar IImu Antropologi. Jakarta: PT Rineka Cipta.

Poerwanto, Hari, 2006. Kebudayaan dan Lingkungan Dalam Perspektif Antropologi. Yogyakarta: Pustaka Pelajar.

Sedyawati, 2014. Kebudayaan di Nusantara Dari Keris, Tor-tor, Sampai Industri Budaya. Depok: Komunitas Bambu. 